\title{
PENGEMBANGAN RUANG TERBUKA HIJAU DENGAN PENDEKATAN KOTA HIJAU DI KOTA KANDANGAN
}

\author{
Developing Green Open Space with Green City Concept at \\ Kandangan City
}

\author{
Jamilah Hayati ${ }^{1}$, Santun R P Sitorus ${ }^{2}$, Siti Nurisjah ${ }^{3}$ \\ Diterima : 20 September $2013 \quad$ Disetujui : 29 Oktober 2013
}

\begin{abstract}
Abstrak : Berdasarkan ketentuan Undang-undang No. 26 Tahun 2007 tentang Penataan Ruang, setiap daerah harus menyediakan $30 \%$ dari luas wilayahnya sebagai ruang terbuka hijau (RTH), yang terbagi atas $20 \%$ RTH publik dan 10\% RTH privat. Kementerian Pekerjaan Umum mengembangkan Program Pengembangan Kota Hijau (P2KH) untuk mendukung pelaksanaan mandat UU tersebut. Penelitian ini bertujuan untuk mengidentifikasi dan memprediksikan kebutuhan RTH publik di Kota Kandangan dan menyusun arahan untuk pengembangannya menggunakan pendekatan Konsep Kota Hijau. Kebutuhan RTH dihitung berdasarkan luas wilayah, jumlah penduduk dan indeks kenyamanan (THI). Hasil penelitian menunjukkan indeks kenyamanan Kota Kandangan masih berada pada kisaran nyaman. Berdasarkan luas wilayah, Kota Kandangan membutuhkan 735,39 ha lahan untuk RTH publik. Berdasarkan jumlah penduduk, Kota Kandangan memerlukan 170,81 ha. Atribut Kota Hijau yang digunakan adalah Green Open Space. Dilihat dari Zoning Regulation Kota Kandangan, masih perlu penambahan area untuk RTH publik dalam bentuk sabuk hijau
\end{abstract}

\section{Keywords: Program Pengembangan Kota Hijau, Ruang Terbuka Hijau, RTH publik}

\begin{abstract}
According to Act No 26/2007 about Spatial Planning, each region is required to provide $30 \%$ of its territory as green open space (RTH), sharing of $20 \%$ as public RTH and $10 \%$ as private RTH. Ministry of Public Works introduced the Green City Development Program (P2KH) to assist the implementation of the mandate of this Act. This study aims to identify and predict the needs of public RTH in Kandangan City and organize referrals for expansion using Green City approach. The needs of RTH is calculated based on vast territory, population and comfort index. Comfort index of Kandangan City are in comfortable range. Based on vast territory, it takes 735,39 ha land for public RTH. Based on population, Kandangan City requires 170,81 ha. Atribute of Gren City approach used is Green Open Space. Compared with Zoning, Regulation, there should be more area needed for public RTH as green belt.
\end{abstract}

Keywords: Green City Development Program, Green Open Space, Public RTH

\footnotetext{
${ }^{1}$ Program Magister Ilmu Perencanaan Wilayah, Faperta Institut Pertanian Bogor

${ }^{2}$ Program Studi Ilmu Perencanaan Wilayah, Departemen Ilmu Tanah dan Sumberdaya Lahan, Faperta, Institut Pertanian Bogor

${ }^{3}$ Departemen Arsitektur Lanskap, Faperta, Institut Pertanian Bogor

Jl. Meranti, Kampus IPB, Dramaga Bogor, 16680
} 


\section{Pendahuluan}

Ruang Terbuka Hijau (RTH) merupakan bagian penting dalam penataan ruang kota karena memiliki fungsi dan manfaat antara lain (1) fungsi ekonomi dari nilai jual tanaman atau sebagai tempat usaha bagi warga kota; (2) fungsi biofisik terkait fungsi ekologis dan perlindungan fisik karena hubungan timbal antara RTH dan lingkungan sekitarnya; (3) fungsi arsitektural terkait estetika lingkungan; dan (4) fungsi sosial untuk peningkatan kualitas kehidupan masyarakat.

Konsep Kota Hijau muncul dilatarbelakangi pertumbuhan kota yang begitu cepat dan mengakibatkan permasalahan perkotaan seperti berkurangnya luasan ruang terbuka hijau serta fenomena perubahan iklim (Ernawi 2012). Konversi lahan dari RTH menjadi lahan terbangun mengakibatkan munculnya fenomena Urban Heat Island (UHI) di kawasan perkotaan. Penelitian Bowler et al. (2010) membuktikan bahwa suhu udara di bawah pohon lebih rendah daripada di area terbuka. Zhou et al. (2011) menegaskan bahwa persentase penutupan vegetasi merupakan faktor terpenting untuk mengurangi efek UHI.

Kota Kandangan adalah ibukota Kabupaten Hulu Sungai Selatan (Kab. HSS). Posisinya yang strategis pada jalur transportasi barang dari pelabuhan Batulicin menuju Banua Lima, membuat kota ini giat membangun berbagai infrastruktur fisik yang diperlukan. Jumlah penduduknya semakin meningkat dari 57.755 jiwa pada tahun 2006 menjadi 62.782 jiwa pada tahun 2010 dengan laju pertumbuhan 1,63\% per tahun (BPS HSS 2006 dan 2011). Pada periode 2008 - 2010, terjadi peningkatan jumlah lahan terbangun dari $9,54 \%$ menjadi $16,74 \%$. Selama periode ini terjadi peningkatan suhu rata-rata tahunan dari 26,79 ${ }^{\circ} \mathrm{C}$ menjadi $27,36^{\circ} \mathrm{C}$ sehingga kenyamanan kota berkurang.

Pemerintah daerah Kab. HSS (Pemkab HSS) menyadari pentingnya upaya untuk mempertahankan jumlah RTH untuk kenyamanan masyarakat. Oleh karena itu Pemkab HSS mencanangkan Gerakan Kandangan Bersih dan Hijau pada bulan Maret 2012. Tapi keseriusan Pemkab HSS ini belum didukung oleh perencanaan yang memadai. Nurisjah (2005) menyatakan bahwa dalam perencanaan dan pengembangan fisik RTH Kota untuk dapat mencapai fungsi dan tujuan yang diinginkan ada empat hal yang harus diperhatikan yaitu: (1) luas minimum yang diperlukan, (2) lokasi lahan kota yang potensial dan tersedia untuk RTH, (3) bentuk yang dikembangkan dan (4) distribusinya dalam kota.

Penelitian ini bertujuan untuk: (1) Mengidentifikasi dan memetakan RTH Eksisting Kota Kandangan, (2) Menganalisis kebutuhan RTH Kota Kandangan berdasarkan luas wilayah, jumlah penduduk dan kenyamanan thermal, (3) Menyusun arahan pengembangan RTH Kota Kandangan.

\section{Metode Penelitian}

\section{Lokasi dan Waktu Penelitian}

Kota Kandangan secara geografis terletak di 2०45’10” - 2॰48’47” Lintang Selatan dan 115॰14'47” - 115॰17’49” Bujur Timur. Luas kawasan Kota Kandangan seluas 3.696,92 ha. Penelitian ini dilaksanakan selama 6,5 bulan, mulai pertengahan bulan April 2013 sampai dengan Oktober 2013, meliputi persiapan penelitian, pengumpulan data, tabulasi dan analisis data, penyusunan arahan pengembangan dan penyusunan tesis.

\section{Bahan dan Alat}

Bahan yang digunakan dalam penelitian ini adalah data primer dan data sekunder dengan rincian sebagai berikut:

a. Data Primer, yaitu Data Distribusi Suhu Isotermal hasil pengukuran langsung di lapangan dan Data Kelembaban Relatif 
b. Data Sekunder, meliputi Peta Administrasi Kota Kandangan, Citra resolusi tinggi dari http://www.bing.com/maps 2010 microsoft corporation, Peta Zoning Regulation/Rencana Penggunaan Lahan Kota Kandangan, Surat Keputusan Bupati tentang Penetapan RTH Publik Kabupaten Hulu Sungai Selatan, Data Jumlah penduduk masing-masing desa/kelurahan di Kota Kandangan tahun 2006 - 2011, Data suhu dan kelembaban rata-rata bulanan tahun 2002 - 2012.

Alat yang digunakan adalah berupa hardware dan software yaitu: Laptop, Kamera Digital, Termohigrometer (Digital Thermo-Hygro tipe E1) untuk mengukur suhu udara dan kelembaban relatif, GPS Garmin 60csx untuk penentuan titik pengamatan, Termometer udara Tecpel 315 type $\mathrm{K}$ untuk mengukur suhu udara, Borang/formulir wawancara dan kuisioner untuk mengetahui preferensi masyarakat, Software ArcGIS 9.3 dan Excell 2007.

\section{Analisis Data}

\section{Analisis Kebutuhan RTH}

1. Kebutuhan RTH Berdasarkan Luas Wilayah

Kebutuhan berdasarkan luas wilayah dihitung berdasarkan UU No. 26 Tahun 2007 tentang Penataan Ruang, yaitu sebesar 30\% dari total luas wilayah, dengan proporsi $20 \%$ berupa RTH publik dan $10 \%$ RTH privat.

2. Kebutuhan RTH Berdasarkan Jumlah Penduduk

Untuk memprediksikan jumlah penduduk di masa yang akan datang, dilakukan dengan menggunakan regresi linear

Di mana:

$$
y=a+b x
$$

$\mathrm{y}=$ Jumlah penduduk pada tahun ke-

$\mathrm{a}$ dan $\mathrm{b}=$ Konstanta

$\mathrm{x} \quad=$ tahun ke-

Ditjen Penataan Ruang (2008) menetapkan standar luas minimum kebutuhan RTH perkotaan secara kuantitatif didasarkan pada jumlah penduduk adalah $20 \mathrm{~m}^{2}$ per kapita yang didistribusikan dalam berbagai tingkat hierarki (Tabel 1).

Tabel 1 Penyediaan RTH Berdasarkan Jumlah Penduduk

\begin{tabular}{|c|c|c|c|c|c|}
\hline No & $\begin{array}{l}\text { Unit } \\
\text { Lingungan }\end{array}$ & Tipe RTH & $\begin{array}{c}\text { Luas } \\
\text { minimal/unit } \\
\left(\mathrm{m}^{2}\right)\end{array}$ & $\begin{array}{c}\text { Luas } \\
\text { minimal/kapita } \\
\left(\mathrm{m}^{2}\right)\end{array}$ & Lokasi \\
\hline 1 & 250 jiwa & Taman RT & 250 & 1,0 & $\begin{array}{l}\text { Di tengah lingkungan } \\
\text { RT radius } 100-200 \mathrm{~m}\end{array}$ \\
\hline 2 & 2.500 jiwa & Taman RW & 1.250 & 0,5 & $\begin{array}{l}\text { Di pusat kegiatan RW } \\
\text { radius } 200-300 \mathrm{~m}\end{array}$ \\
\hline 3 & 30.000 jiwa & Taman Kelurahan & 9.000 & 0,3 & $\begin{array}{l}\text { Dikelompokkan dengan } \\
\text { sekolah/pusat } \\
\text { kelurahan }\end{array}$ \\
\hline 4 & 120.000 jiwa & $\begin{array}{l}\text { Taman } \\
\text { Kecamatan }\end{array}$ & 24.000 & 0,2 & $\begin{array}{l}\text { Dikelompokkan dengan } \\
\text { sekolah/pusat } \\
\text { kecamatan }\end{array}$ \\
\hline & & Pemakaman & disesuaikan & 1,2 & tersebar \\
\hline \multirow[t]{3}{*}{5} & 480.000 jiwa & Taman kota & 144.000 & 0,3 & Di pusat wilayah/kota \\
\hline & & Hutan kota & disesuaikan & 4,0 & $\begin{array}{l}\text { Di dalam/kawasan } \\
\text { pinggiran }\end{array}$ \\
\hline & & $\begin{array}{l}\text { Untuk Fungsi } \\
\text { tertentu }\end{array}$ & disesuaikan & 12,5 & $\begin{array}{l}\text { Disesuaikan dengan } \\
\text { kebutuhan }\end{array}$ \\
\hline
\end{tabular}

Sumber: Ditjen Penataan Ruang (2008) 
3. Kebutuhan Berdasarkan Temperature Humidity Index (THI)

Temperature Humidity Index (THI) yang dikenal sebagai indeks kenyamanan merupakan metode untuk mengetahui adanya cekaman panas dan menetapkan efek dari kondisi panas tersebut pada kenyamanan manusia dengan mengkombinasikan parameter suhu dan kelembaban udara. Kondisi nyaman apabila sebagian energi manusia dibebaskan untuk kerja produktif dan upaya pengaturan suhu tubuh berada pada level minimal (Effendy 2007). Menurut hasil penelitian Mom (1947) dalam Effendy (2007) indeks kenyamanan di Indonesia berkisar pada nilai $20-26$. Nilai THI didapatkan menggunakan rumus yang dikembangkan oleh Nieuwolt (1975) dalam Rushayati (2011):

$$
T H I=(0,8 \times T)+\left(\frac{R H \times T}{500}\right)
$$

Di mana:

THI = Temperature Humidity Index

$\mathrm{T}=\quad$ Suhu udara $\left({ }^{\circ} \mathrm{C}\right)$

$\mathrm{RH} \quad=\quad$ Kelembaban Relatif $(\%)$

Wardhani (2006) merumuskan perhitungan dalam menentukan proporsi penambahan RTH untuk mencapai indeks kenyamanan $\leq 26$ berdasarkan proporsi luas wilayah dan nilai THI hingga didapatkan:

$$
\begin{aligned}
& P \text { luas }=\frac{L}{\Sigma L} \\
& \text { PTHI = PLuas } \times \text { THI. } \\
& \text { THIn }=\text { PTHI }-(\text { SPTHI }-26) \\
& p=\text { PLuas }-\left(\frac{(\Sigma P T H I-26)}{\Sigma P T H I}\right) \\
& L R T H=L-\left(p \times \sum L\right) \\
& P R T H=\left(\frac{L R T H}{\Sigma L}\right) \times 100 \text {. }
\end{aligned}
$$

Di mana:

Pluas = Proporsi luas $(\%)$

$\mathrm{PTHI}=$ Proporsi THI

$\Sigma$ PTHI $=$ Jumlah proporsi THI

THIn $=$ THI Nyaman

LRTH = Luas Penambahan RTH

$\mathrm{L} \quad=$ Luas (i)

$\mathrm{p} \quad=$ Proporsi supaya nyaman $(\%)$

$\Sigma \mathrm{L} \quad=$ Jumlah Luas

$\mathrm{PRTH}=$ Proporsi penambahan RTH $(\%)$

\section{Tahap Penyusunan Arahan Pengembangan RTH Kota Kandangan}

Penyusunan arahan pengembangan RTH Kota Kandangan difokuskan untuk memenuhi kebutuhan RTH publik sebesar 20\% dari luas wilayah. Pendistribusiannya dan bentuk RTH mempertimbangkan jumlah dan kepadatan penduduk. Indeks kenyamanan thermal dipertimbangkan untuk menentukan jenis tanaman yang akan digunakan.

Selain itu, penyusunan arahan pengembangan RTH Kota Kandangan juga memperhatikan pertimbangan-pertimbangan sebagai berikut:

1. Pendekatan Konsep Kota Hijau

Arahan ini mengidentifikasikan atribut kota hijau yang akan dijadikan fokus pengembangan, dan strategi yang bisa ditempuh untuk mewujudkan RTH 30\% dari luas wilayah kota.

2. Analisis Ketersediaan Lahan

Analisis ketersediaan lahan dilakukan untuk melihat lokasi lahan kota yang potensial dan tersedia untuk pengembangan RTH publik di masa yang akan datang berdasarkan Zoning Regulation yang telah ditetapkan oleh Pemkab HSS dalam RDTRK. 


\section{Hasil Dan Pembahasan}

\section{Identifikasi dan Pemetaan RTH Eksisting Kota Kandangan}

Mayoritas RTH Kota Kandangan merupakan RTH privat berupa lahan pertanian perkotaan yaitu kebun campuran (48,17\%) dan sawah (35.09). RTH publik sendiri hanya menempati $0,22 \%$ dari seluruh luas wilayah kota dengan luas 8,23 ha dengan rincian berupa taman dan hutan kota seluas 5,75 ha, jalur hijau jalan seluas 1,02 ha, dan RTH dengan fungsi tertentu seluas 1,46 ha. Selain jumlah dan luas RTH publik yang belum memadai, distribusi lokasi RTH publik tersebut pun masih belum terstruktur dengan baik. RTH Publik yang ada umumnya terpusat di wilayah pusat kota, dan sepanjang jalur transportasi utama. Daerah-daerah pinggiran terutama di sebelah timur dan barat Kota Kandangan tidak memiliki ketersediaan RTH publik (Gambar 1).

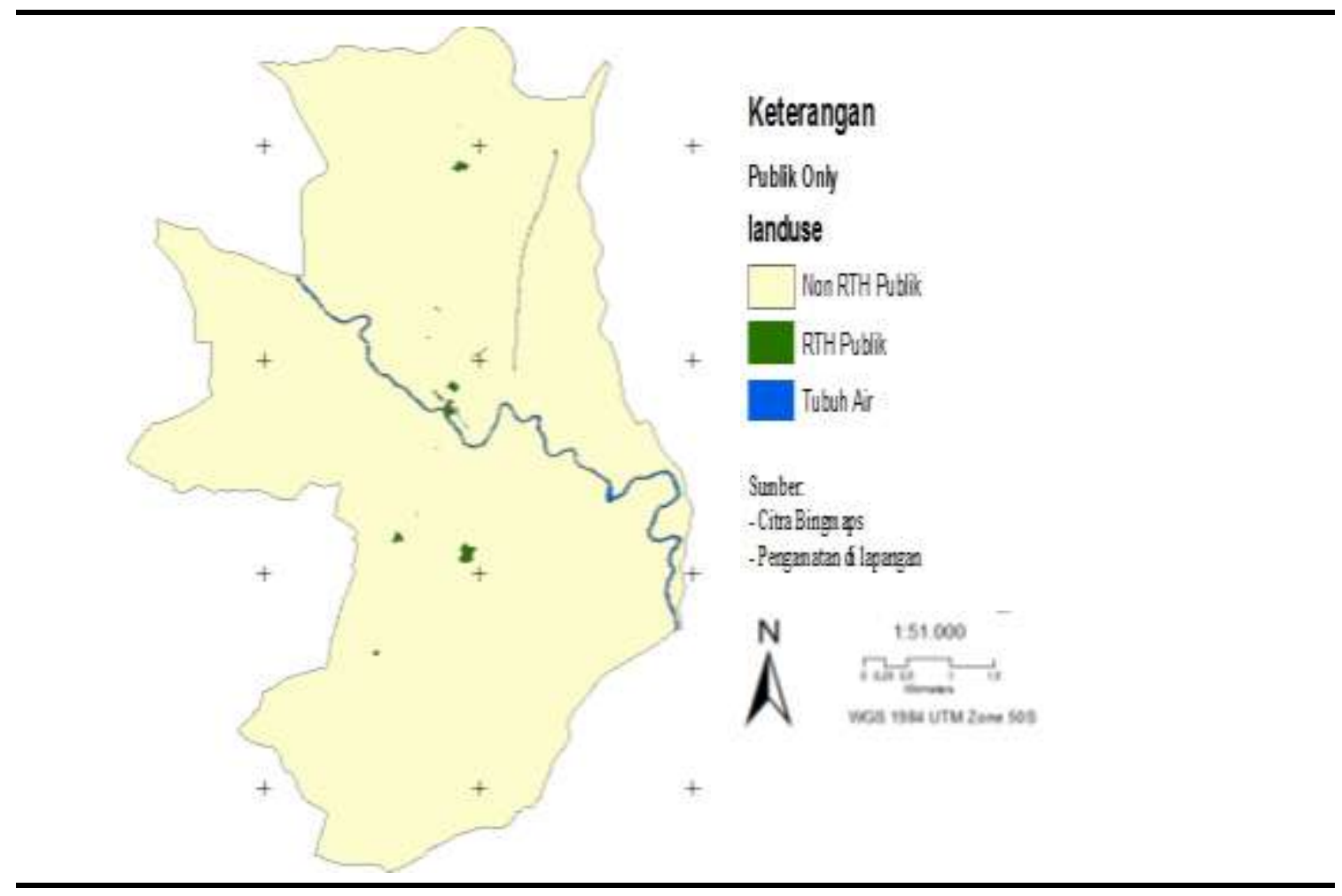

Gambar 1 Peta penyebaran RTH publik Kota Kandangan

\section{Kebutuhan RTH Kota Kandangan}

\section{Kebutuhan Berdasarkan Luas Wilayah}

Berdasarkan standarisasi UU No. 26 Tahun 2007 tentang Penataan Ruang, diperlukan 30\% dari luas wilayah berupa RTH, atau sebesar 1.103,09 ha. Kebutuhan ini sebenarnya sudah tercukupi oleh ketersediaan lahan pertanian di wilayah kota Kandangan berupa kebun campuran seluas $1.612,81 \mathrm{Ha}$, atau $43,86 \%$ dari luas kota. Namun ketentuan bahwa 20\% dari luasan tersebut adalah RTH publik, masih belum terpenuhi. Luas RTH publik Kota Kandangan baru 8,23 ha atau 0,22\% dari luas kota. Ketersedian RTH publik ini masih kurang dari yang seharusnya yaitu 20\% atau 739,38 hektar. Dengan demikian, pemerintah daerah masih harus menyediakan RTH publik seluas 731,15 hektar lagi. Dengan asumsi semua kecamatan menyumbangkan porsi yang sama untuk RTH yaitu 20\% 
dari luas wilayah masing-masing, maka distribusi kebutuhan RTH masing-masing kecamatan bisa dilihat pada Tabel 2 .

Tabel 2 Kebutuhan RTH berdasarkan luas wilayah

\begin{tabular}{llrrrr}
\hline No & Kecamatan & $\begin{array}{r}\text { Luas Wilayah } \\
\text { (ha) }\end{array}$ & $\begin{array}{r}\text { Kebutuhan RTH Publik } \\
\text { 20\% Luas Wilayan (ha) }\end{array}$ & $\begin{array}{r}\text { Ketersediaan } \\
\text { RTH Publik (ha) }\end{array}$ & $\begin{array}{c}\text { Selisih untuk } \\
\text { Penambahan }\end{array}$ \\
\hline 1 & Kandangan & $2.466,54$ & 4934,31 & 6,88 & $-486,43$ \\
2 & Padang Batung & 524,40 & 104,88 & 0,00 & $-104,88$ \\
3 & Angkinang & 12,49 & 2,50 & - & $-2,50$ \\
4 & Sungai Raya & 636,02 & 127,20 & 1,35 & $-125,85$ \\
5 & Simpur & 57,47 & 11,49 & - & $-11,49$ \\
& JUMLAH & $3.696,92$ & $\mathbf{7 3 9 , 3 8}$ & $\mathbf{8 , 2 3}$ & $\mathbf{- 7 3 1 , 1 5}$ \\
\hline
\end{tabular}

\section{Kebutuhan Berdasarkan Jumlah Penduduk}

Jumlah penduduk Kota Kandangan berkembang mengikuti persamaan regresi $y=1079 x+56.273$. Berdasarkan persamaan tersebut, maka diperkirakan jumlah penduduk Kota Kandangan pada tahun 2032 mencapai 85.426 jiwa. Jumlah ini meningkat sebesar 42\% dari jumlah penduduk Kota Kandangan berdasarkan sensus tahun 2010 sebesar 62.782 jiwa. Dengan demikian, kebutuhan RTH Kota Kandangan pada tahun 2032 berdasarkan jumlah penduduk secara total adalah 170,85 ha. Untuk memenuhi kebutuhan RTH publik berdasarkan jumlah penduduk, pemerintah daerah harus menyediaan RTH seluas 162,58 ha (Tabel 3)

Tabel 3 Kebutuhan RTH berdasarkan jumlah penduduk ( $20 \mathrm{~m}^{2}$ per kapita)

\begin{tabular}{clcccc}
\hline No & Kecamatan & $\begin{array}{c}\text { Proyeksi Jumlah } \\
\text { Penduduk Tahun } \\
\text { 2032 (jiwa) }\end{array}$ & $\begin{array}{c}\text { Kebutuhan RTH } \\
\text { Publik (ha) }\end{array}$ & $\begin{array}{c}\text { Ketersedian RTH } \\
\text { Publik (ha) }\end{array}$ & $\begin{array}{c}\text { Selisih untuk } \\
\text { Penambahan (ha) }\end{array}$ \\
\hline 1 & Kandangan & 56.506 & 113,01 & 6,88 & $-106,13$ \\
2 & Padang Batung & 11.891 & 23,78 & 0,00 & $-23,78$ \\
3 & Angkinang & 3.745 & 7,49 & 0,00 & $-7,49$ \\
4 & Sungai Raya & 11.868 & 23,74 & 1,35 & $-22,38$ \\
5 & Simpur & 1.416 & 2,83 & 0,00 & $-2,83$ \\
& Jumlah & $\mathbf{8 5 . 4 2 6}$ & $\mathbf{1 7 0 , 8 5}$ & $\mathbf{8 , 2 3}$ & $-162,62$ \\
\hline
\end{tabular}

\section{Kebutuhan Berdasarkan Indeks Kenyamanan}

Berdasarkan pengukuran di lapangan, nilai rata-rata THI Kota Kandangan berkisar antara 24,70 - 26,26. Nilai terendah berada pada penggunaan lahan berupa kebun campuran dan tertinggi adalah pasar. Dengan menggunakan rumus turunan dari Wardhani (2007), diperoleh hasil bahwa nilai proporsi THI Kota Kandangan adalah 24,99. Dengan demikian, Kota Kandangan saat ini masih berada pada kisaran nyaman (Tabel 4). Distribusi indeks kenyamanan Kota Kandangan bisa dilihat pada Gambar 2.

Dari Tabel 4 terlihat bahwa penggunaan lahan dengan tutupan vegetasi berupa pohon dan tubuh air memiliki nilai kenyamanan yang lebih baik daripada lahan terbangun atau tutupan vegetasi rendah. Dengan demikian, untuk memperbaiki kenyamanan thermal terutama pada daerah-daerah yang nilai THI-nya $>26$ perlu penambahan RTH berupa tanaman peneduh dan tubuh air.

\section{Penyusunan Arahan Pengembangan RTH Kota Kandangan}

Kondisi eksisting RTH Kota Kandangan menunjukkan bahwa RTH Kota Kandangan didominasi oleh RTH Privat, sedangkan RTH publik masih sangat kurang. Oleh karena itu, upaya pengembangan RTH Kota Kandangan diarahkan untuk meningkatkan jumlah RTH publik sehingga memenuhi ketentuan $20 \%$ dari luas wilayah. Jumlah kebutuhan RTH Kota 
Kandangan berdasarkan jumlah penduduk adalah 170,85 ha. Untuk meningkatkan kenyamanan thermal, dibutuhkan penambahan tanaman peneduh dan tubuh air.

Tabel 4 Proporsi THI dan Luas Penambahan RTH Kota Kandangan

\begin{tabular}{lcccccccc}
\hline $\begin{array}{l}\text { Penggunaan } \\
\text { Lahan }\end{array}$ & Luas (ha) & $\begin{array}{c}\text { Proporsi } \\
\text { Luas }\end{array}$ & THI & $\begin{array}{c}\text { Proporsi } \\
\text { THI }\end{array}$ & THIn & p & LRTH & PRTH \\
\hline $\begin{array}{l}\text { Kebun } \\
\text { Campuran }\end{array}$ & 1658,606 & 0,441 & 24,697 & 10,888 & 11,903 & 0,481 & $-152,748$ & $-4,060$ \\
Kebun & & & & & & & & \\
Sayuran & 65,696 & 0,017 & 25,496 & 0,445 & 1,460 & 0,058 & $-152,748$ & $-4,060$ \\
Lapangan & & & & & & & & \\
Pasar & 6,381 & 0,002 & 25,362 & 0,043 & 1,057 & 0,042 & $-152,748$ & $-4,060$ \\
Permukiman & 585,973 & 0,001 & 26,263 & 0,019 & 1,034 & 0,041 & $-152,748$ & $-4,060$ \\
$\quad$ RTH Publik & 8,273 & 0,156 & 25,362 & 3,950 & 4,965 & 0,196 & $-152,748$ & $-4,060$ \\
Tanah & 2,445 & 0,002 & 24,849 & 0,055 & 1,069 & 0,043 & $-152,748$ & $-4,060$ \\
Terbuka & & & 24,846 & 0,016 & 1,031 & 0,041 & $-152,748$ & $-4,060$ \\
Sawah & 1317,672 & 0,350 & 25,151 & 8,809 & 9,824 & 0,391 & $-152,748$ & $-4,060$ \\
Semak & 86,539 & 0,023 & 25,038 & 0,576 & 1,590 & 0,064 & $-152,748$ & $-4,060$ \\
Belukar & & & & & & & & \\
Terminal & 1,796 & 0,000 & 25,594 & 0,012 & 1,027 & 0,041 & $-152,748$ & $-4,060$ \\
Tubuh Air & 26,016 & 0,007 & 24,820 & 0,172 & 1,186 & 0,048 & $-152,748$ & $-4,060$ \\
JUMLAH & 3762,139 & 1,000 & & 24,986 & & & $-152,748$ & $-4,060$ \\
\hline
\end{tabular}

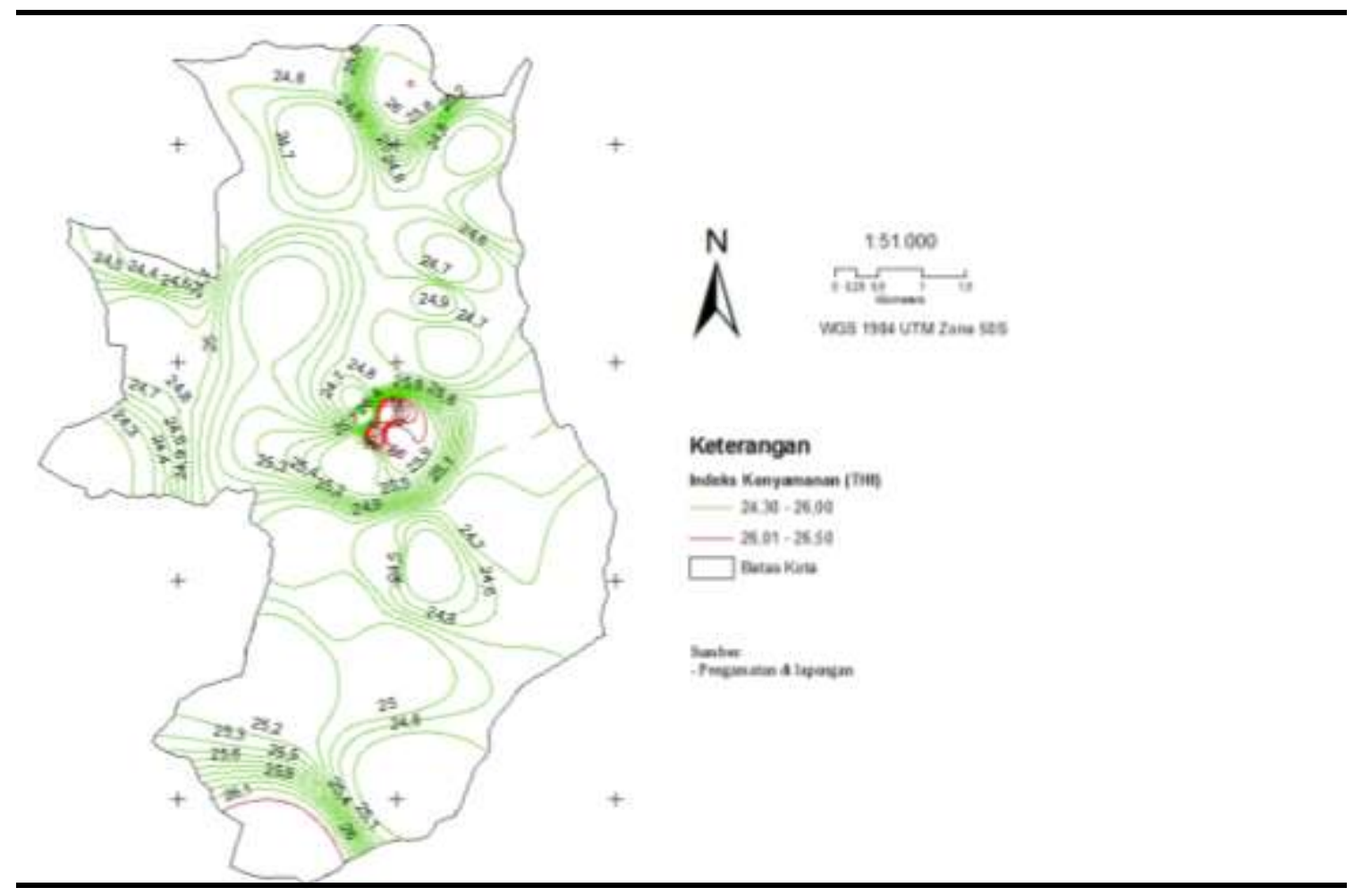

Gambar 2 Distribusi Indeks Kenyamanan Kota Kandangan

\section{Pendekatan Konsep Kota Hijau}

Dalam KemenPU (2012), kegiatan P2KH untuk periode 2011 - 2014 difokuskan pada atribut Green Open Spaces. Untuk pengembangan RTH Kota Kandangan, diutamakan 
adalah atribut Green Open Space. Strategi yang bisa diambil untuk pengembangan RTH Kota Kandangan adalah

a. Membangun lahan hijau $(h u b)$ baru pada lahan-lahan yang telah direncanakan

b. Mengembangkan koridor ruang terbuka hijau (link) di sepanjang jalan arteri dan kolektor primer, serta sabuk hijau di sekeliling Kota Kandangan

c. Peningkatan kualitas RTH melalui refungsi RTH eksisting dengan penanaman pohon peneduh pada fasilitas olahraga dan pemakaman umum

Secara spasial strategi penambahan luas RTH publik berdasarkan pendekatan konsep Kota Hijau dengan atribut Green Open Space ini bisa dilihat pada Gambar 3.

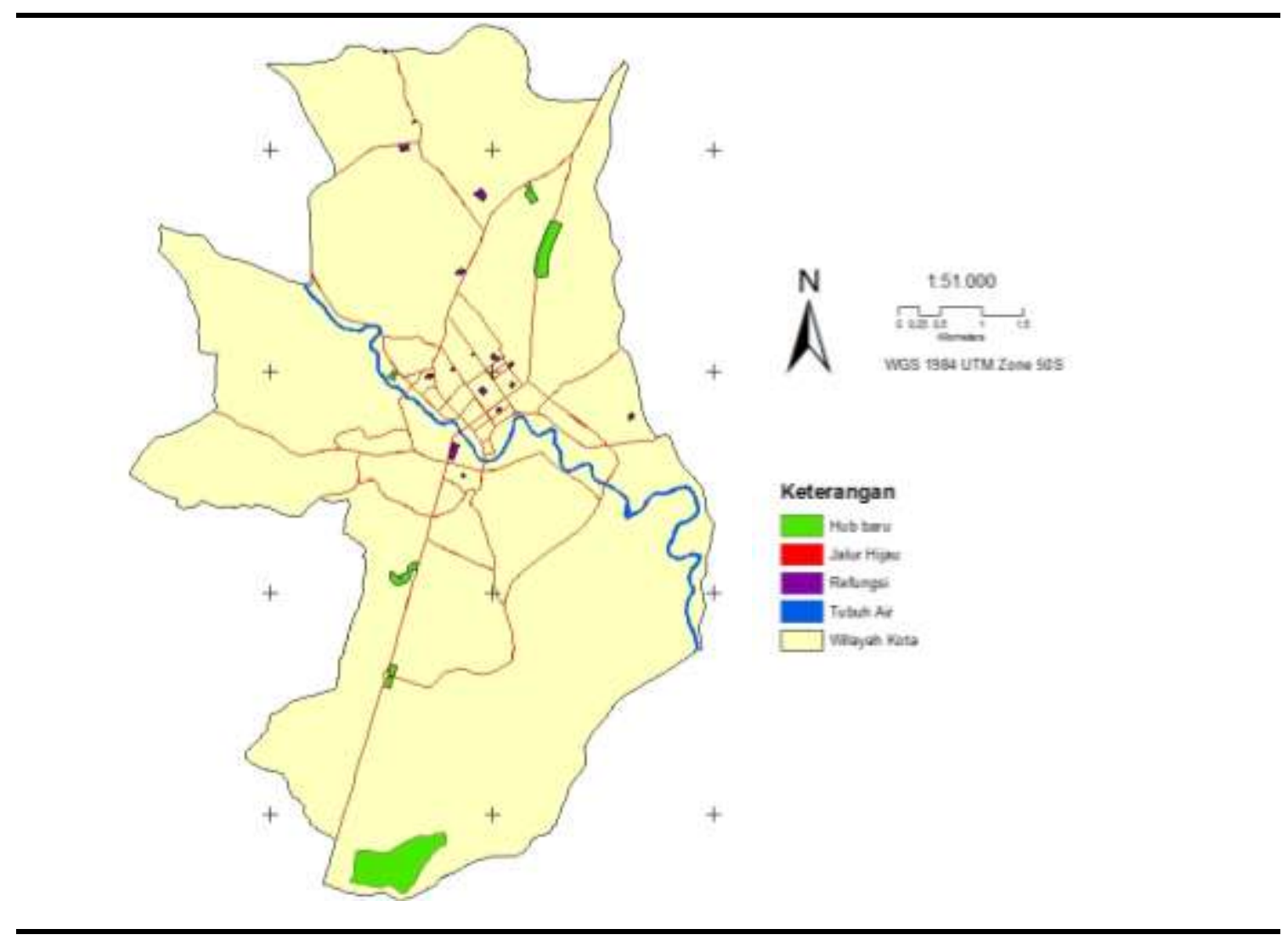

Gambar 3 Strategi penambahan RTH publik berdasarkan atribut Green Open Space

\section{Analisis Ketersediaan Lahan untuk RTH}

Dalam rencana Zoning Regulation Kota Kandangan, ditetapkan wilayah pengembangan RTH publik adalah daerah sempadan sungai amandit dan pada kawasan rencana RTH Perkantoran seluas 93,76 ha. Selain itu, disediakan juga lahan untuk sarana rekreasi dan olahraga di beberapa wilayah konsentrasi pemukiman seluas 60,36 ha (Gambar 3). Secara total, luas wilayah yang direncanakan untuk RTH publik adalah 154,12 ha. Jumlah ini masih belum mencukupi kebutuhan berdasarkan jumlah penduduk, terlebih lagi berdasarkan luas wilayah. Oleh karena itu, perlu strategi lain untuk meningkatkan jumlah RTH publik Kota Kandangan

Penekanan strategi pengembangan RTH publik Kota Kandangan berdasarkan Zoning Regulation adalah menjaga kesinambungan fungsi RTH eksisting yang didominasi oleh RTH privat berupa lahan pertanian. Karena itu, strategi yang ditawarkan adalah:

1. Pemberian insentif kepada masyarakat yang bersedia mempertahankan lahannya tetap sebagai lahan hijau. 
2. Peningkatan produktivitas lahan pertanian terutama sawah dengan pembangunan irigasi teknis sehingga petani bisa becocok tanam lebih dari sekali dalam setahun.

3. Mengembangkan model pertanian tumpang sari antara tanaman pohon produktif seperti buah-buahan, kelapa, karet, dsb dengan tanaman pendek semusim seperti sayur-sayuran dan palawija untuk menambah penghasilan petani.

4. Pengembangan wisata pertanian pada wilayah yang dianggap potensial.

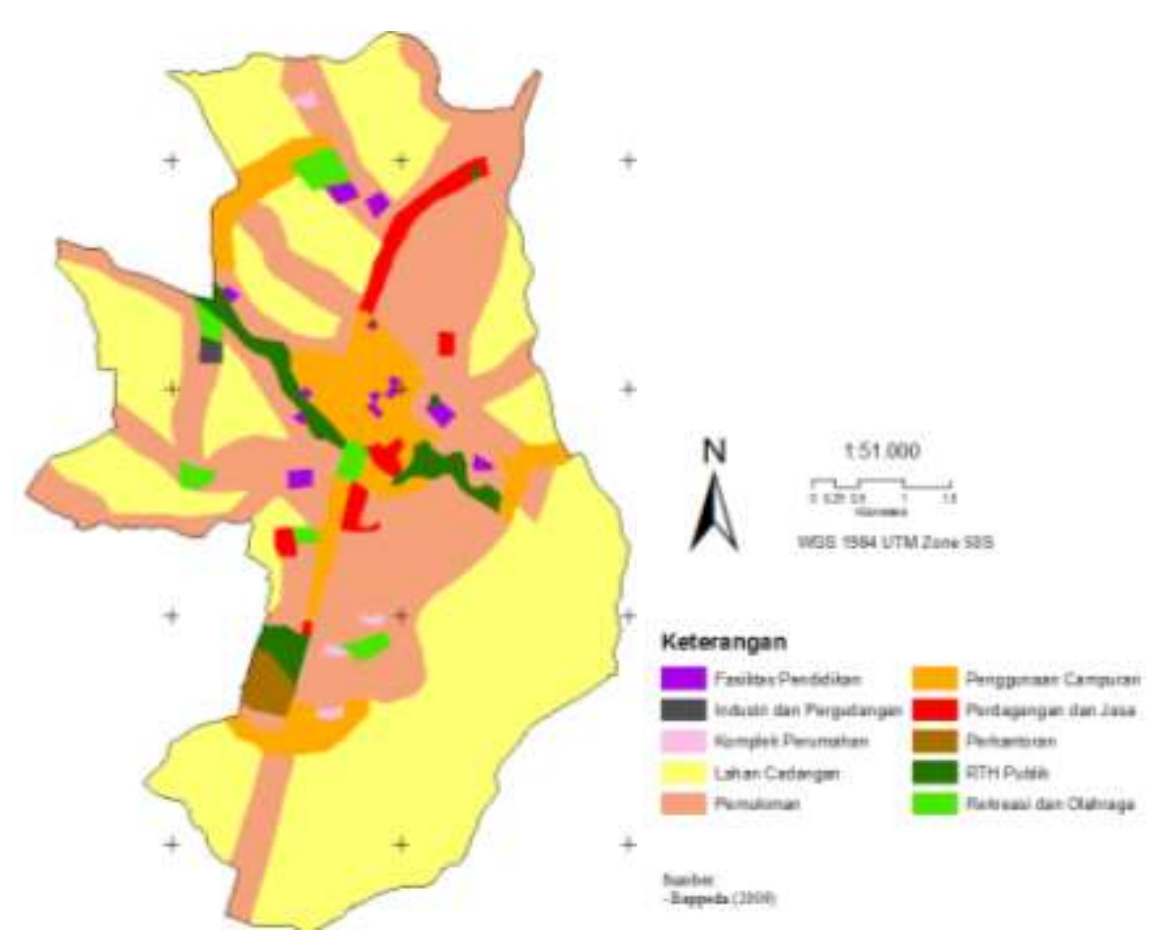

Sumber: Bappeda (2009)

Gambar 4 Peta Zoning Regulation Kota Kandangan tahun 2010 - 2029

\section{Arahan Pengembangan RTH Kota Kandangan}

Dengan mempertimbangkan kebutuhan RTH Kota Kandangan berdasarkan luas wilayah, jumlah penduduk dan kenyamanan thermal, maka pengembangan RTH Kota Kandangan dikategorikan dalam 3 wilayah, yaitu wilayah pusat kota, dalam kota dan pinggiran kota, dengan pertimbangan kepadatan penduduk.

1. Wilayah pusat kota

Wilayah pusat kota memiliki karakteristik yaitu kepadatan penduduk yang tinggi, sedangkan lahan potensial untuk pengembangan RTH terbatas. Penambahan RTH publik di wilayah ini diarahkan untuk fungsi ekologis dan fungsi arsitektural dalam bentuk jalur hijau jalan di sepanjang jalan arteri dan jalan kolektor primer. Selain itu juga perlu dilakukan refungsi RTH eksisting dengan menambahkan jumlah pohon peneduh. Jenis tanaman yang dipilih adalah jenis tanaman peneduh yang juga bisa menyerap polusi, seperti angsana, trembesi,dan tanjung serta jenis-jenis tanaman hias untuk memperindah kota.

2. Wilayah dalam kota

Wilayah ini memiliki karakteristik di mana kepadatan penduduk sedang, sedangkan lahan potensial untuk pengembangan RTH masih cukup luas. Penambahan RTH 
publik di wilayah ini diarahkan untuk fungsi sosial dan fungsi ekonomi dalam bentuk RTH taman dan hutan kota meliputi berbagai fasilitas rekreasi dan olahraga. Pilihan jenis tanamannya adalah jenis tanaman peneduh yang banyak memproduksi oksigen seperti pohon kupu-kupu, tanjung dan kiara payung dan jenis tanaman hias untuk keindahan serta rumput sebagai alas untuk beraktivitas.

3. Wilayah pinggiran kota

Karakteristik wilayah ini adalah kepadatan penduduk rendah, tetapi lahan potensial untuk pengembangan RTH masih sangat luas. Penambahan RTH publik diarahkan untuk fungsi ekologis dan ekonomi dalam bentuk jalur sebagai sabuk hijau (green belt) yang mengelilingi kota. Pilihan jenis tanamannya adalah jenis-jenis tanaman produktif seperti buah-buahan, kelapa, karet, kayu manis, dan sebagainya.

Pemetaan spasial dari arahan ini bisa dilihat pada Gambar 5.

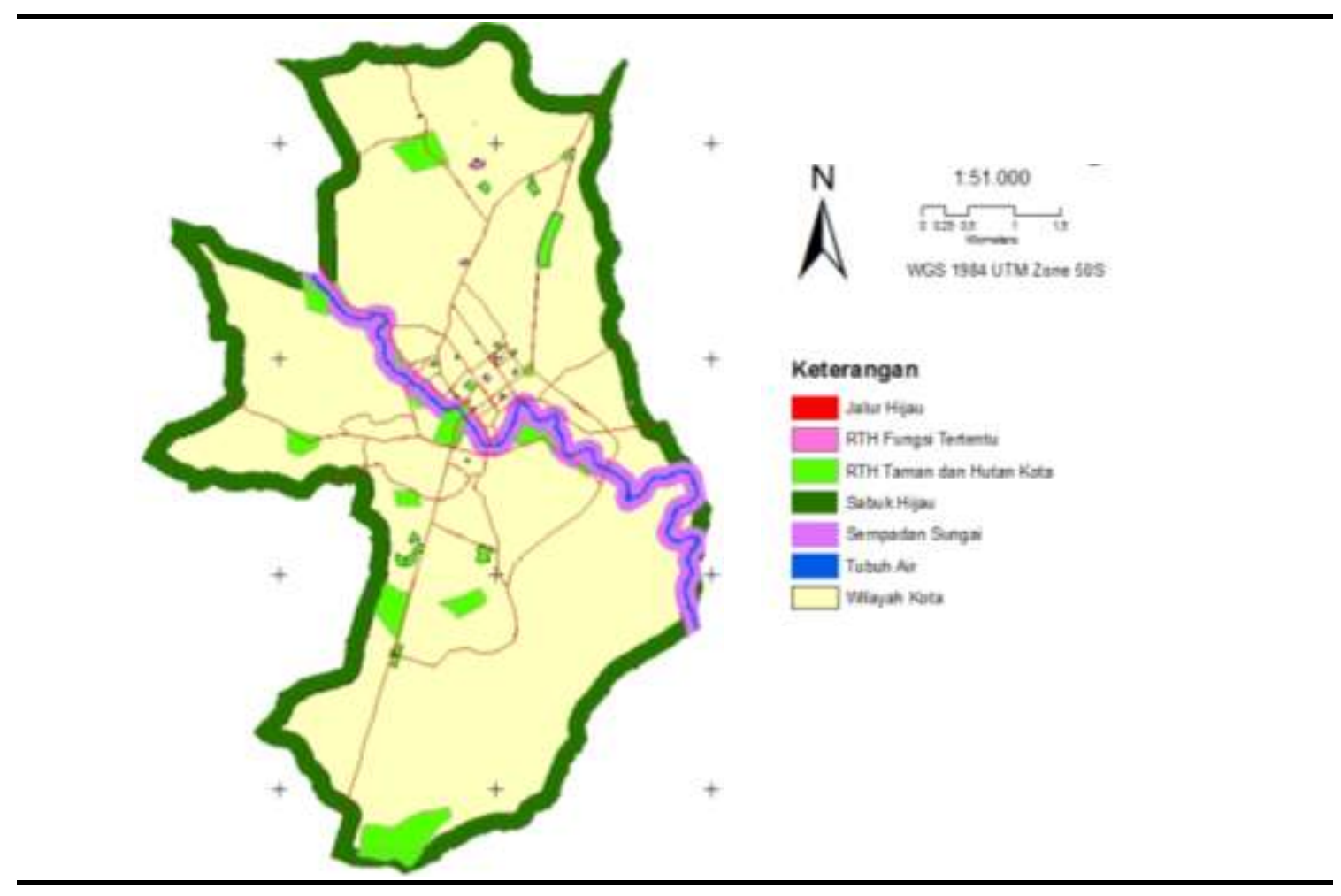

Gambar 5 Arahan pengembangan RTH Publik Kota Kandangan

\section{Kesimpulan Dan Saran}

\section{Kesimpulan}

1. RTH Kota Kandangan didominasi oleh RTH Privat berupa lahan pertanian. Ketersediaan RTH Publik hanya mencapai 0,22\% dari luas Kota Kandangan dalam bentuk taman dan hutan kota seluas 5,75 ha, jalur hijau jalan seluas 1,02 ha dan RTH dengan fungsi tertentu seluas 1,46 ha. RTH publik ini terdistribusi secara tidak merata yaitu di kawasan pusat kota dan jalan utama saja.

2. Kebutuhan RTH publik Kota Kandangan berdasarkan luas wilayah adalah 731,15 ha dan berdasarkan jumlah penduduk seluas 162,62 ha. Kebutuhan ini didistribusikan berdasarkan wilayah kecamatan yaitu kecamatan Kandangan seluas 106,13 - 486,43 ha; kecamatan Padang Batung seluas 23,78 - 104,88 ha; kecamatan Angkinang seluas 
2,50 - 7,49 ha; kecamatan Sungai Raya seluas 22,38 - 125.85 ha dan kecamatan Simpur seluas $2,83-11,49$ ha.

3. Arahan pengembangan RTH Kota Kandangan berdasarkan pendekatan Konsep Kota Hijau adalah menggunakan atribut Green Open Space yaitu membangun lahan hijau (hub) baru, mengembangkan koridor hijau, peningkatan kualitas RTH kota dan menghijaukan bangunan. Lahan pengembangan yang disediakan oleh pemerintah daerah melalui Zoning Regulation belum mencukupi kebutuhan, sehingga perlu penambahan jumlah RTH Publik terutama di daerah pinggiran kota untuk dijadikan sabuk hijau (green belt).

\section{Saran}

1. Perlu penetapan kawasan preservasi dan ketentuan pembebasan jalur hijau di sepanjang sempadan sungai Amandit sebagai RTH Publik dalam bentuk peraturan daerah

2. Mengingat maraknya pengembangan komplek-komplek perumahan baru sejak tahun 2008 sampai sekarang, perlu adanya pengaturan penetapan $\mathrm{KDH}$ dalam setiap pengurusan IMB dan kewajiban bagi pengembang untuk menyediakan fasilitas RTH Publik di setiap komplek perumahan.

3. Pada kawasan komersial yang dipenuhi oleh bangunan sangat sulit menyediakan lahan untuk RTH publik, karena itu perlu sosialisasi mengenai bangunan hijau berupa roof garden dan green wall serta pemberian insentif bagi pemilik bangunan yang menerapkan konsep bangunan hijau.

\section{Daftar Pustaka}

[Bappeda HSS] Badan Perencanaan dan Pembangunan Daerah Hulu Sungai Selatan. 2009. Revisi Rencana Detail Tata Ruang Kota (RDTRK) Kandangan Tahun 2010 - 2029. Kandangan (ID). Pemerintah Kabupaten Hulu Sungai Selatan.

Bowler DE, Buyung-Ali L, Knight TM, Pullin AS. 2010. Urban Greening to Cool Towns and Cities: A Systematic Review of The Empirical Evidence. Landscape and Urban Planning 2010(97):147-155.

[BPS HSS] Badan Pusat Statistik Hulu Sungai Selatan. 2006 Kecamatan Dalam Angka Tahun 2006. Kandangan (ID). Badan Pusat Statistik Hulu Sungai Selatan.

[BPS HSS] Badan Pusat Statistik Hulu Sungai Selatan. 2011 Kecamatan Dalam Angka Tahun 2011. Kandangan (ID). Badan Pusat Statistik Hulu Sungai Selatan.

[Ditjen Penataan Ruang] Direktorat Jenderal Penataan Ruang. 2008. Peraturan Menteri Pekerjaan Umum Nomor 5/PRT/M/2008 tentang Pedoman Penyediaan dan Pemanfaatan Ruang Terbuka Hijau di Kawasan Perkotaan. Jakarta (ID). Departemen Pekerjaan Umum.

Effendy S. 2007. Keterkaitan Ruang Terbuka Hijau dengan Urban Heat Island Wilayah Jabotabek. [disertasi]. Bogor (ID): Institut Pertanian Bogor.

Ernawi IS. 2012. Gerakan Kota Hijau: Merespon Perubahan Iklim dan Pelestarian Lingkungan. Bulletin Tata Ruang. (Januari-Pebruari 2012):4-7.

Kementerian Pekerjaan Umum. 2012. Program Pengembangan Kota Hijau (P2KH) Panduan Pelaksanaan 2012. Jakarta (ID). Kementerian Pekerjaan Umum.

Nurisjah S. 2005. Penilaian Masyarakat terhadap Ruang Terbuka Hijau (RTH) Wilayah Perkotaan: Kasus Kotamadya Bogor. [disertasi]. Bogor (ID): Institut Pertanian Bogor.

Rushayati SB, Alikodra HS. Dahlan EN, Purnomo H. 2011. Pengembangan Ruang Terbuka Hijau Berdasarkan Distribusi Suhu Permukaan di Kabupaten Bandung. Forum Geografi. 25(1): 17-26.

Wardhani, DE. 2006. Pengkajian Suhu Udara dan Indeks Kenyamanan dalam Hubungannya dengan Ruang Terbuka Hijau (Studi Kasus Kota Semarang). [skripsi]. Bogor (ID): Institut Pertanian Bogor.

Zhou W, Huang G, Cadenasso ML. 2011. Does Spatial Configuration Matter? Understanding The Effects of Land Cover Pattern on Land Surface Temperature in Urban Landscapes. Landscape and Urban Planning. 2011(102):54-63. 